\title{
Introduction: Chinese women with different government systems
}

\section{Cherlyn Skromme Granrose}

Government policies related to taxation, health, reproduction, welfare, childcare, educational access and non-discrimination in employment affect women's employment directly and indirectly. Policies and laws vary widely in Chinese societies from the egalitarian, socialist provisions of Singapore and Taiwan, to the laissez-faire policy the British advocated for the Hong Kong government. In each of the following chapters we can see the influence on women's employment of some common cultural traditions. We can also begin to discover how these traditions are enacted as they have been influenced by Chinese cultural history and economic differences from $500 \mathrm{BCE}$ to the political events of the twenty-first century.

This volume contains chapters which describe the status of government policies and the status of employed women in different Chinese nationstates at the beginning of the twenty-first century. In addition to a chapter on Singapore, we include the People's Republic of China, Hong Kong and Taiwan (the Republic of China) as separate chapters, even though they are currently considered by some to be a single nation, because each of these entities has a distinctive history as well as different legal and economic systems that provide different options and constraints for women who work for pay outside the domestic sphere.

The volume concentrates on paid work for women and includes discussion of workers in high government and management positions as well as those working in difficult factory or service conditions. The book does not attempt to address uncompensated work even though many women labor for no compensation. It also does not include analyses of the employment concerns of women working in the underground or illegal economy. We hope there are other scholars who will address the concerns of these women in another volume.

For each of the chapters that summarize a specific location, the author listed first is a scholar whose personal background is from the culture being described, to ensure that the interpretation of statistics and laws and government actions is consistent with internal perceptions. In addition to these 
'insider' perspectives, the authors of all chapters have reviewed the work of each chapter in the volume and contributed suggestions from their different perspectives. We chose this process in the hope that through this dialogue of opinions, each work could be strengthened. The final authority, however, has always rested with the credited authors.

The idea for this volume arose out of a symposium proposal for the Academy of Management meetings about Chinese women's lives in different parts of the world. It was shaped by the interests of the women scholars we were able to locate in various Chinese societies and grew to the present volume after almost five years of research, writing, reviewing and editing. Because national statistics are collected in different ways and published in different years using different formats, the authors could not always produce parallel data and information for each country; however each author tried to provide a picture at the beginning of the new century with additional background data from the twentieth century where it was available. The authors also come from different academic cultures that have different views about relevance and appropriateness. We have tried to honor each tradition while creating enough similarity to provide relevant information to the reader. These differences have prevented us from conducting statistical comparisons between entities; however the global picture described of each nation-state can give the reader some sense of possible similarities and differences even with the lack of statistical tests for significant differences.

The book is divided into three sections: Part I, 'Western theory and Chinese culture', provides a theoretical introduction from both Chinese and Western perspectives; Part II, 'Government policies and the employment status of Chinese women', provides summaries from each nationstate; Part III, 'Conclusions', provides a comparative summary. The contributors hope that this work will provide a story of Chinese women at the turn of the twentieth to twenty-first century that will be a useful benchmark for government officials, organizational policy makers, scholars and women themselves to build upon for the rest of the twenty-first century.

The book begins in Part I with 'Theoretical perspectives on women's employment careers in a national government context' by Cherlyn Skromme Granrose, Irene Hau-Siu Chow and Irene K.H. Chew. This chapter outlines major theories of careers of employed women taken primarily from a Western academic tradition. Some might question the need or even propriety of including Western theories in a collection of descriptions about Chinese women; however almost all of the previous empirical and theoretical work on employment of women in the twentieth century has focused on this tradition, and the training of most of the authors of this volume has 
occurred in the Western academic tradition. To ignore this background or to pretend that it has not shaped the perspective of the authors and many readers would be misleading.

It would be equally misleading to ignore the Chinese cultural and scholarly tradition that shapes the everyday lives and assumptions of authors and women and readers of this volume. The Chinese traditional perspective is described in Chapter 2, 'Images of women and government in the Chinese cultural heritage', by Cherlyn Skromme Granrose. By reading from the Western tradition presented in Chapter 1 in juxtaposition to the Taoist, Confucian, Buddhist and Legalist cultural influences presented in Chapter 2, the first two chapters provide the Chinese and Western perspectives that form a foundation for the rest of this volume. Both of these traditions are also used in the concluding chapter, Chapter 8 , to provide different frameworks with which to interpret the authors' findings.

In Part II, the third chapter, 'National policy influence on women's careers in the People's Republic of China', by Yong-Qing Fang, Cherlyn Skromme Granrose and Rita V. Kong (Mei Hui Jiang), begins the descriptive section of different Chinese national systems. This chapter examines legislation, policy and constitutional provisions about women and the status of women in mainland People's Republic of China (PRC) under the current government system of Chinese socialism with market characteristics.

In addition to being the motherland from which most of the women's ancestors in all other chapters come, the nation of the PRC has a unique government history. During the first half of the twentieth century this nation moved from an empire, through a brief period of democracy, to warlord and Kou Min Tang (KMT) governments. In the second half of the twentieth century the current government controlled by the Chinese Communist Party (CCP) has also explored aspects of a market economy. Thus the PRC is the only situation described here where communist and socialist and market political and economic philosophies have all had an influence on the cultural traditions of the Chinese. While the chapter cannot review each of these political periods separately, it describes the situation at the turn of the twenty-first century that resulted from the influences of each of these systems. This chapter also reports the situation of the largest numerical population of Chinese women in the world.

The fourth chapter, 'Women in Taiwan: social status, education and employment', by T.K. Peng and Tsai-Wei Wang describes how the government has experienced influences from the ancient indigenous island culture, Chinese mainland immigration over many years, recent government by the Kuomingtang fleeing the Communist army on mainland China at the end of the 1940s, and finally a non-KMT elected government to start the new century. Because this society has not felt the influence of the CCP, 
or Western colonial rule, it may be closer than the others described here to the evolution of a traditional Chinese culture in a market economic system.

Chapter 5, 'The impact of government policy on working women in Hong Kong', by Irene Hau-Siu Chow, also relates the tale of a Chinese island flooded with immigrants from the Chinese mainland over most of its history. In this case the political system has had a different British Empire colonial history during most of the twentieth century. Hong Kong returned to PRC rule in 1997 but has permitted the territory to maintain the market economy left as the British legacy, with some continuing tension about the extent of independence from PRC influence. Thus we have a Chinese culture influenced by a British view of a free market economy within a colonial political system recently transformed by renewed political influence of the PRC.

'The impact of government and family responsibilities on the career development of working women in Singapore' by Irene K.H. Chew and Naresh Khatri is the sixth chapter. This presents the status of working women on another Chinese-dominated island, this time off the tip of Malaysia, which experienced British colonial rule for the first half of the twentieth century until it became independent from Britain and Malaysia in 1959. The first decade after independence was a time of turmoil, separating from Malaysia and fighting insurgent Chinese Communists. For most of the latter half of the twentieth century the Singaporean government reflected the strong paternalistic and centralized government of a Chinese majority with some influence of the Malay, Indian and British minorities operating under a market economic system.

This section concludes with an in-depth study of the specific implementations of national policies at the local level in one Chinese province near Beijing. 'Women's development in Hebei Province, PRC' by Yong-Qing Fang presents an evaluation of public policy and provides one indication of the problems and triumphs of local efforts to implement policies to support women at the time the international women's conference was meeting in the PRC. This chapter also serves to illustrate both the triumphs and the gaps in policy administration as local governments seek to apply national policy directives.

In Part III of this volume, Chapter 8, 'Chinese women, half the sky, little ground: comparative comments on Chinese women's lives under various government systems', Cherlyn Skromme Granrose uses the theoretical frameworks from the first part of the book to provide an analysis of the effects of the various political systems on the lives of Chinese women and to cast a critical eye toward the descriptive and empirical findings from the different settings. Because it was not possible to obtain trustworthy equivalent statistics that are comparable across countries, the final comparison 
cannot rest on a quantitative analysis of the country data but must examine the collective experience portrayed by the whole chapter from each location. In every case, a clear gap remains between the employment lives of women and of men in each of these Chinese societies, and this gap is clearly tied to gender roles prescribed by family obligations arising from Chinese cultural traditions and gender discrimination that exists in both Chinese and Western societies. The chapter concludes with some recommendations for change captured from each of the authors' work.

The contributors hope that through the juxtaposition of work on women of a similar culture heritage living under different government systems, some scholars, women and government leaders might gain new insights that will benefit Chinese working women wherever they live. 
Cherlyn Skromme Granrose - 9781845428068 Downloaded from PubFactory at 04/26/2023 09:51:52AM via free access 